\title{
Patients' Perception of Generic Drugs at Health Institutions in Trinidad and Tobago
}

\author{
Arlene Villarroel Stuart ${ }^{1,2}$, Madan Mohan Gupta ${ }^{1 *}$, Patricia Sealy ${ }^{1}$ \\ 'School of Pharmacy, Faculty of Medical Sciences, The University of the West Indies, St. Augustine Campus, TRINIDAD \& TOBAGO. \\ 2Unit of Pharmacology, Department of Para clinical Sciences Faculty of Medical Sciences, The University of the West Indies, St. Augustine Campus, TRINIDAD \& TO- \\ BAGO.
}

\begin{abstract}
Background: Generic drugs are manufactured to be similar to their brand name counterparts. They are procured by healthcare organizations and governments to provide accessible and affordable medicines for patients worldwide. The objective of this study was to investigate the perception of patients regarding generic drugs. Methods: A non-randomized, crosssectional, convenient sample study design was employed. Patients were interviewed, at selected chronic disease clinics at health institutions in the North Central region of Trinidad, using a questionnaire to garner their perception of generic drugs. Results: While $30.43 \%$ of patients knew the names of their prescribed medicines, $74.75 \%$ did not know what a generic drug was. After patients were appropriately educated, both the single-item question on perception and the total perception domain demonstrated 'good', followed by 'excellent' general perception of generic drugs.
\end{abstract}

Conclusion: The use of generic drugs can provide cost-effective, therapeutic benefits to the healthcare sector. Consequently, patient education on the advantages of generic drugs can improve their acceptance.

Key words: Perception, patients, generic drugs, brand name drugs, Trinidad\&Tobago

Correspondence :

Dr. Madan Mohan Gupta, School of Pharmacy, Faculty of Medical Sciences, The University of the West Indies, St. Augustine, TRINIDAD \& TOBAGO.

Phone: +1-868-6452640

Email: mmingupta@gmail.com

DOI: 10.5530/jyp.2017.9.72

\section{INTRODUCTION}

The Government of Trinidad and Tobago (TT) implemented the Chronic Disease Assistance Programme (CDAP) in 2003; CDAP aimed to decrease the overcrowding at public sector pharmacies, and to increase the access of free medicines to patients. The programme provides medicines to treat various chronic medical conditions including diabetes, asthma, cardiac diseases and epilepsy. CDAP decreased the burden of cost associated with the procurement of prescription medications for the Government, as some drugs on this essential list were primarily generic preparations..$^{1-2}$

Generic drugs are described as drug products marketed after the expiry of the patent of the innovator (brand) drug and is manufactured to be similar to the innovator in dose, dosage form, indication, active ingredients and drug performance. The World Health Organization (WHO) has suggested essential medicines to be accessible and affordable; nevertheless, patients and healthcare professionals both have unfavourable perceptions of generic drugs. ${ }^{3-5}$

Perception is triggered after exposure to a stimulus whether external (environmental) or internal (personality and beliefs); stimuli are then processed via measures such as selection, organization and interpretation. The acquired perception data is thereafter interpreted by the individual as real and from which an action is performed. ${ }^{6,7}$ Various factors such as culture, ethnicity and prior experience gives each person their individuality; as a consequence, these parameters also influence perception. Analysing patients' perception about generic drugs will allow researchers to target specific areas of concern in order to assist in the therapeutic management of patients. ${ }^{8}$

Shrank et al investigated patients' perception about generic drugs and found that although patients acknowledged the cost-benefit of generic drugs, they were less inclined to take the preparations themselves. ${ }^{9,10}$
Education and communication were recommended as solutions to this problem. Dunne et al also highlighted education as a measure to increase generic acceptance and referenced pharmacovigilance to monitor issues with generic drug use. ${ }^{3}$ Similarly, Singal et al researched the cost of generic drugs and suggested that the quality of generic pharmaceuticals be publicly acknowledged. Shrank et al observed a relationship between the use of generic drugs and communication, especially with respect to generic substitution. The authors emphasized that education can improve this concern. Additionally, Shrank et al highlighted patients' anxiety about safety and efficacy, both of which encouraged scepticism regarding the use of generic drugs. ${ }^{10-14}$

The increasing use of generic drugs is a worldwide phenomenon. ${ }^{15}$ This study aimed to explore patients' perception of generic drugs at chronic disease clinics of healthcare institutions in the North Central region of Trinidad.

\section{METHODS}

\section{Study Design and Sampling Tool}

A non-randomized, cross-sectional, convenient sample study design was employed. The study was conducted from June to August in 2010 at selected chronic disease clinics at health institutions in the North Central region of Trinidad. The interview-type questionnaire included 3-/5-/6-point Likert and Visual Analog Scales (VAS) and open-ended questions. ${ }^{16-19}$ Written consent was acquired and persons were asked the extent to which they agreed or disagreed with statements about generic medicines. Zero and ten on the VAS represented 'poor' and "excellent" respectively; VAS measured patients' perception of generic drugs prior to presenting three scenarios about generic drugs. The first scenario referred to the packaging of the generic medication; while the second 
and third scenarios, respectively, focussed on a change in the name and appearance relative to the innovator medication.

The questionnaire was validated among supervisors and colleagues, pre-piloted and piloted at a health centre and was subsequently adjusted prior to enrolling participants into the study. The education about the meaning for generic drugs was given to the all the patients before the study as well as it had explained them about the questionnaire that was distributed to them for their answer. The patients were asked a question about all the detailed of questionnaire.

The sensitization or educated method used in this study was three scenarios described within the questionnaire followed by questions about generic drugs. These questions referred to issues such as cost, safety, appearance, efficacy, switching and communication of generic drugs. The first scenario referred to the packaging of the generic medication; while the second and third scenarios, respectively, focused on a difference in the name and a change of appearance relative to the innovator medication.

The study was described as cross-sectional because of how the patients were selected for the main objective of the study which is the perception of generic drugs. The sensitization or education of patients was included in the study to obtain data about the perception of generic drugs, as well as, to determine whether sensitization or education of generic drugs can have an impact on patients' understanding about generic drugs

\section{Sampling Method}

Patients and the institutions of the North Central Regional Health Authority (NCRHA) were conveniently selected; the latter was from the Ministry of Health's website. The criteria included participants of at least eighteen years of age who were affiliated with a public health institution. The study was approved by the Ethics Committees of the Faculty of Medical Sciences of The University of the West Indies, the NCRHA and the selected institutions.

\section{Data Collection and Statistical Analysis}

Verification of patients' medical condition and medications were confirmed using the patients' medical file after completion of interviews for that particular day. Some questions of the same subject were combined to form domains; responses for domains and the single-item for perception were divided into four groups - poor, fair, good and excellent. Cronbach's alpha was used to confirm the reliability of the domains with accepted coefficients $\geq 0.8 .^{20-24}$ Data were entered into Microsoft Office Excel ${ }^{\oplus} 2007$ for Windows ${ }^{\oplus}$ and analysed in Statistical Package for the Social Science version 12; specifically, descriptive and inferential statistics.

\section{RESULTS}

\section{Demographics}

While one hundred and fifty-three patients were enrolled, only ninetynine patients completed the questionnaire for a response rate of $65 \%$. The majority of the patients were $\geq 60$ years $(53.06 \%)$ and between the ages 51-60 years $(28.57 \%)$. The main occupations were housewives $(36.08 \%)$, and retirees/pensioners (34.02\%). The participants were mainly females (69.39\%) and most were of African (42.86\%) and mixed (35.71\%) ethnicity. The highest level of education attained was primary (63.92\%) then secondary (28.87\%) schooling. The greatest number of patients attended a public healthcare facility for $\leq 10$ years $(70.10 \%)$. The approximate total annual household income was $\$ 20,000$ to $<\$ 35,000$ / year $(40.00 \%)$; then $<\$ 20,000 /$ year $(38.95 \%)$.

\begin{tabular}{ccc}
\hline Table 1: List of medical conditions reported by patients & \\
\hline Medical Condition & $\mathbf{n}$ & $\%$ \\
\hline Hypertension & 64 & 65.31 \\
Diabetes Mellitus & 44 & 44.90 \\
Heart disorders & 21 & 21.43 \\
All types of pain & 14 & 14.29 \\
Hypercholesterolemia & 10 & 10.20 \\
Kidney disorders & 6 & 6.12 \\
Other circulatory disorders & 3 & 3.06 \\
Thyroid & 3 & 3.06 \\
Asthma & 3 & 3.06 \\
Liver & 2 & 2.04 \\
Infections & 2 & 2.04 \\
Cancer & 2 & 2.04 \\
Epilepsy & 1 & 1.02 \\
Other & 13 & 13.27 \\
\hline
\end{tabular}

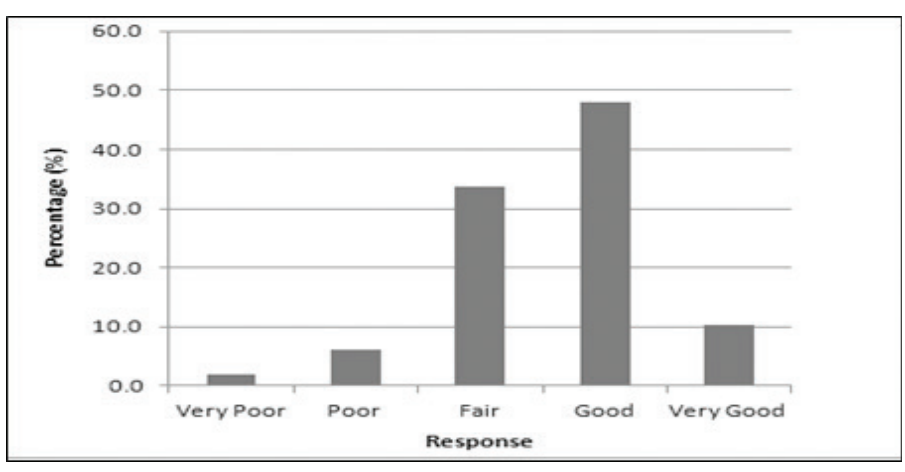

Figure 1: Rating of general health status

\section{Medical condition and medicines}

Most patients considered their general health status to be "good" (47.96\%) or "fair" (33.67\%) and the majority of patients had cardiovascular related conditions. (Table 1 and Figure 1) Patients (30.43\%) knew the names of their prescribed medications, while $39.13 \%$ and $30.43 \%$, respectively, stated either "did not know" or "knew somewhat" the names of their medicines. The main medicines reported were Aspirin (51.58\%), HMGCoA (3-hydroxy-3-methylglutaryl coenzyme A) reductase inhibitors (Statins, 42.11\%), Angiotensin Converting Enzyme Inhibitors (ACEIs, 41.05\%), Diuretics (35.79\%) and Metformin (Biguanide, 29.47\%). Most patients $(79.17 \%)$ agreed that they were satisfied with their current treatment.

\section{Would take generic drugs}

Scenarios were used to examine whether the patient would take the generic drug given by the pharmacist. In scenario $1,51 \%$ agreed with using the medication if the packaging was different. In scenario $2,54 \%$ of patients would use the medication if the name of the drug was different. In scenario $3,56 \%$ of patients disagreed with the use of generic drugs if there was a change in the drug's appearance. Seventy-five percent of patients were concerned about differences in colour, size, shape and packaging of their medications. Sixty-seven percent of participants were uncomfortable receiving a generic drug to treat their condition, while $74 \%$ would rather not take generic drugs compared to the brand name drugs. 


\section{Knowledge}

The respondents $(74.75 \%)$ did not know initially what a generic drug was. Twenty-four $(45.83 \%)$ patients described generic drugs as inferior and rated generic drug as "fair" (55.56\%). After patients received education on generic drugs, patients reclassified generics as either "fair" (20.00\%), "good" (46.32\%) or "very good" (20.00\%). (Figure 2 )

\section{Cost}

A large number of the patients agreed (87.88\%) that generic drugs were less expensive than brand name drugs, but disagreed (70.71\%) with the use of generics because of cost savings.

\section{Safety}

Patients (78.79\%) demonstrated their concern about the safety of generic drugs, and agreed that the use of generics caused "worse" (51.02\%) or "more" (51.02\%) side effects than brand name drugs. The safety domain of generic drugs revealed that $36.5 \%$ of patients perceived generic drugs to be 'fair'. (Figure 3)

\section{Effectiveness}

Patients (80.81\%) were not satisfied with the effectiveness of generic drugs. They agreed $(81.82 \%)$ that brand name drugs were more effective than generic drugs.

\section{Substitution}

Patients (72.73\%) did not support the substitution of a brand name drug for a generic while $57.14 \%$ disagreed with substituting one generic drug for another. Participants agreed that the pharmacist should substitute only with a doctor's $(84.85 \%)$ and/or patient's $(76.29 \%)$ consent; and $68.69 \%$ agreed that "substitution" can have negative results. Patients (56.57\%) disagreed that the "active ingredient" of the generic drug was the same as that of the brand name drug.

\section{Perception}

The VAS exhibited most patients at $5(25.3 \%)$ then 4 (11.1\%). The singleitem for perception and the perception domain, respectively, demon-

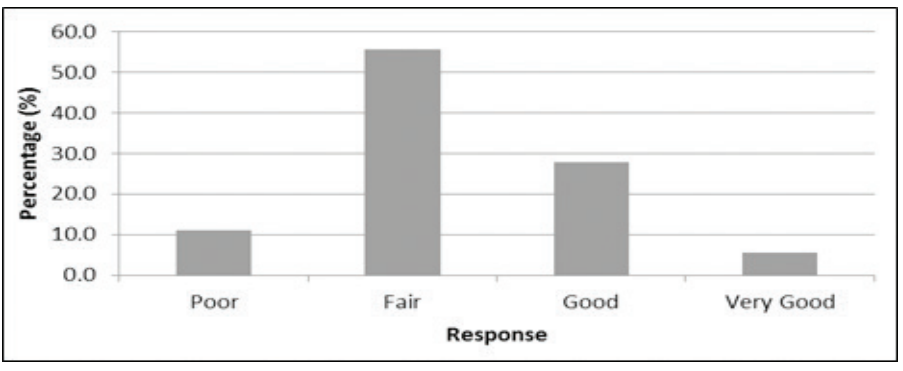

Figure 2: Prior understanding rating of a generic drug

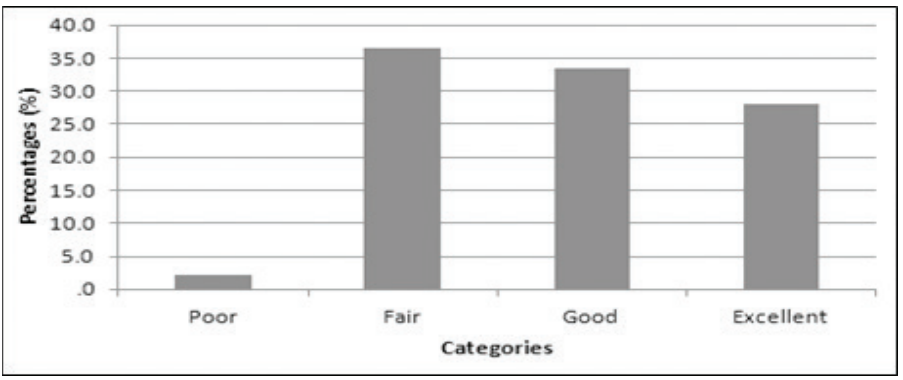

Figure 3: Patients' safety domain for generic drugs

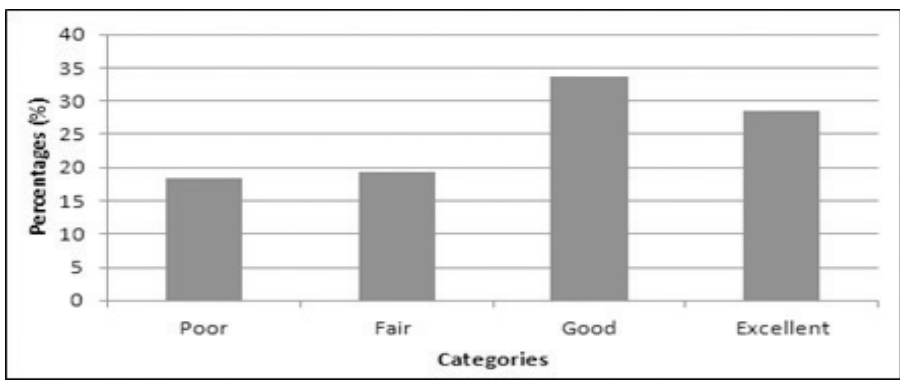

Figure 4: Patients' perception of generic drugs (Single-item)

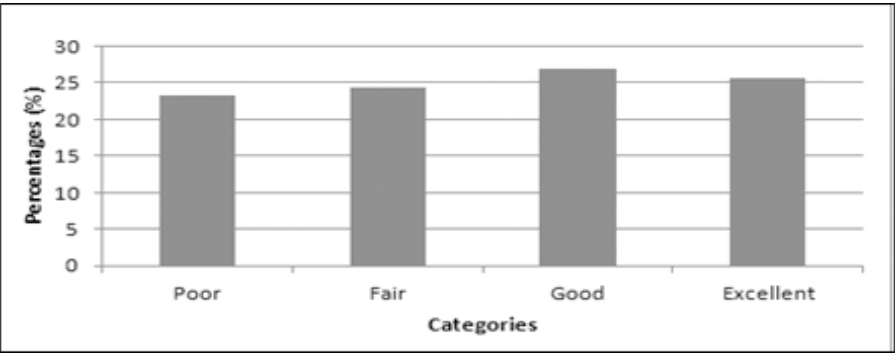

Figure 5: Perception domain of generic drugs among patients

Table 2: Logistic regression analysis

\begin{tabular}{ccc}
\hline Description & $\begin{array}{c}\text { Single-item Perception } \\
(p \text {-value })\end{array}$ & $\begin{array}{c}\text { Perception Domain } \\
(p \text {-value })\end{array}$ \\
\hline Safety & $0.014 ; 0.002 ; 0.046$ & $0.018 ; 0.016$ \\
Would take & 0.071 & $0.006 ; 0.061$ \\
Efficacy & 0.003 & $0.029 ; 0.003$ \\
Switch & 0.072 & - \\
\hline
\end{tabular}

strated $33.7 \%$ and $26.8 \%$ of patients had a good perception of generic drugs. (Figures 4 and 5) The logistic regression analysis for perception included "safety", "would take", "efficacy" and "substitution", with significance at $5 \%$ and $10 \%$ levels (Table 2).

\section{Communication}

Patients stated that their doctor (90.63\%) and pharmacist $(81.25 \%)$ did not talk to them about generic drugs. Nevertheless, patients' first choice educator for their medications was a doctor (88.66\%) followed by a pharmacist (77.78\%). Patients (90.69\%) indicated that the physician was the main person they would talk to if any of their medications were not working or caused side effects.

\section{DISCUSSION}

Our research findings illustrated that although most patients were satisfied with their current treatment, there were some patients who were uncomfortable receiving a generic drug and preferred the brand name counterpart. Additionally, patients' perception of generic medication was affected by differences in appearance, and safety and efficacy concerns.

The majority of patients in our study were educated to the primary school level, $\geq 65$ years and female. This is consistent with the statistics of the TT population and WHO which stated more males than females received education to the primary and secondary school levels, and most of the elderly population were not educated. Garcia et al (2012) found 57.7\% of elderly had been educated to the primary level and accounted for the low health literacy in this cohort. ${ }^{23}$ The authors suggested that physicians 
and healthcare professionals ensure that patients understand the information communicated. In our study patients preferred doctors to educate them about their medicines; nevertheless, an educator role can be shared amongst healthcare personnel and government who partake in the therapeutic management of patients. The pre-/post-sensitization about generic drugs did increase the patients' self-assessed understanding from "fair" (55.56\%) to "good" (46.32\%) or "very good" (20.00\%). More women were interviewed than males in our research, probably because more women visit the public healthcare institutions than males in Trinidad and Tobago.

In 2008,378 adults per 100,000 population between the age 30 to 70 years died from cardiovascular diseases and diabetes. These findings and others were similar to our findings where patients' medical conditions were primarily hypertension, diabetes and heart disease.

Shrank et al (2009) demonstrated that most patients agreed generic drugs cost less than the innovator medication; this was also observed in our study. These researchers also found that patients were not willing to take generic drugs themselves; however, some (56\%) indicated that persons should increase their use of these products. Our findings illustrated that many patients had a "good" perception about generic drugs, but preferred not to take the drug if there was a difference in the external features of the product. Additionally, some patients also indicated that the brand name drug was more effective than the generic product. Substitution of medicines by pharmacists was not supported by patients, who preferred substitution to be permitted only by the physician and/ or patient. This finding was similarly observed by Shrank et al (2009). Generally, substitution, safety and efficacy concerns significantly influence patients' perception of generic drugs. The sample size in our study was small, thereby limiting our ability to extrapolate the findings to the general population.

The method used to acquire data was unique for this study because it incorporated various aspects including the use of one question about patients' perception compared to more than one question for this same parameter; it explored patients' understanding of generic drugs before and after sensitization/education. This study used scenarios to obtain data about patients' perception as oppose to direct questions which was mainly found in other articles

\section{CONCLUSION}

In this study, patients demonstrated a "good" perception of generic drugs and education predominantly enhanced patients' perception. Patients require assurance by policy-makers, physicians and pharmacists that the generic drugs offered to the public are of satisfactory quality; this initiative could improve patients' health outcomes. Investigating patients' perception may assist in the therapeutic management of their chronic diseases, and particularly drug adherence. Generic drugs are valuable in any healthcare system, but it is of little benefit if only few acknowledge its advantages.

Generic drugs are widely used in this twin island and some knowledge about patients' perception can have a significant effect on how to assist in the management of patients. As well as, to make persons responsible for purchasing of drugs for the national formulary aware of such data and hence see a need to implement measures to appropriately assess medications used on the formulary.

\section{AUTHORS' CONTRIBUTION}

All the authors were involved in collection and analysing the data and preparing the manuscript.

\section{ACKNOWLEDGEMENT}

The authors wish to acknowledge the patients, physicians, pharmacists, nurses and those in authority at the healthcare Institutions of the North Central region of Trinidad for their support and assistance. Authors also wish to thank Dr. L Montane Jaime, Dr Yuri Clement, Dr RG Maharaj and Dr George Legall ( Faculty of the University of the West Indies) for their support to the study. Additionally, authors are grateful to The University of the West Indies for the printing of questionnaires.

\section{CONFLICTS OF INTEREST}

There are no conflicts of interest.

\section{ABBREVIATION USED}

TT: Trinidad and Tobago; CDAP: Chronic Disease Assistance Programme; WHO: World Health Organization; VAS: Visual Analog Scales; NCRHA: North Central Regional Health Authority.

\section{REFERENCES}

1. National Insurance Property Development Company Limited (NIPDEC) Pharmaceutical. Chronic Disease Assistance Program (CDAP). Report 2011. [Last accessed on July 8, 2016]

2. Ministry of Health of the Government of the Republic of Trinidad and Tobago. Drug Safety. Available from: http://www.health.gov.tt/news/newsitem. aspx?id=323. [Last accessed on July10, 2016]

3. Dunne S, Shannon B, Dunne C, Cullen W. A review of the differences and similarities between generic drugs and their originator counterparts, including economic benefits associated with usage of generic medicines, using Ireland as a case study. BMC Pharmacol Toxicol. 2013;14(1):1. doi:10.1186/2050-651114-1. https://doi.org/10.1186/2050-6511-14-1.

4. Gagne JJ, Choudhry NK, Kesselheim AS. Comparative effectiveness of generic and brand-name statins on patient outcomes. Ann Intern Med. 2014;161 (6):400-7. https://doi.org/10.7326/M13-2942; PMid:25222387.

5. Haas JS, Phillips KA, Gerstenberger EP, Seger AC. Potential savings from substituting generic drugs for brand-name drugs: medical expenditure panel survey, 1997-2000. Ann Intern Med. 2005;142(11):891-7. https://doi.org/10.7326/00034819-142-11-200506070-00006 ; PMid:15941695.

6. Patel A, Gauld R, Norris P, Rades T. This body does not want free medicines: south african consumer perceptions of drug quality. Health Policy Plan. 2010;25(1):61-9. https://doi.org/10.1093/heapol/czp039 ; PMid:19726560.

7. Nelson AA, Gagnon JP. Brand substitution the consumer's viewpoint. J Am Pharm Assoc. 1975;15(7):382-5. https://doi.org/10.1016/S0003-0465(15)32085-1.

8. Alrasheedy AA, Hassali MA, Stewart K, Kong DCM, Aljadhey H, Ibrahim MI, et al. Patient knowledge, perceptions, and acceptance of generic medicines: a comprehensive review of the current literature. Patient Intell. 2014;6:1-29.

9. Shrank WH, Hoang T, Ettner SL, Glassman PA, Nair K, DeLapp D, et al. The implications of choice: prescribing generic or preferred pharmaceuticals improves medication adherence for chronic conditions. Arch Intern Med. 2006;166(3):332-7. https://doi.org/10.1001/archinte.166.3.332 ; PMid:16476874.

10. ShrankWH, Cox ER, Fischer MA, Mehta J, Choudhry NK. Patients' perceptions of generic medications. Health Aff (Millwood). 2009;28:546-56. doi: 10.1377/ hlthaff.28.2.546. https://doi.org/10.1377/hlthaff.28.2.546.

11. Shrank WH, Cadarette SM, Cox E, Fischer MA, Mehta J, Brookhart AM, et al. Is there a relationship between patient beliefs or communication about generic drugs and medication utilization? Med Care. 2009;47(3):319-25. doi: 10.1097/ MLR.0b013e31818af850. https://doi.org/10.1097/MLR.0b013e31818af850.

12. Howland RH. What makes a generic medication generic. J Psychosoc Nurs Ment Health Serv. 2009;47(12):17-20. https://doi.org/10.3928/02793695-20090101-07: https://doi.org/10.3928/02793695-20091103-99 : https://doi.org/10.3928/0279369520090401-06:https://doi.org/10.3928/02793695-20090508-01 : https://doi.org/ 10.3928/02793695-20090930-06 : https://doi.org/10.3928/02793695-2009072201 : https://doi.org/10.3928/02793695-20090201-05.

13. Stefanucci JK, Gagnon KT, Lessard DA. Follow your heart: Emotion adaptively influences perception. Soc Personal Psychol Compass. 2011;5(6):296-308. https:// doi.org/10.1111/j.1751-9004.2011.00352.x; PMid:21731579 PMCid:PMC3124782.

14. Krämer K, Bente G, Luo S, Pfeiffer UJ, Han S, Vogeley K. Influence of ethnic group-membership and gaze direction on the perception of emotions. a crosscultural study between germany and china. PLoS One. 2013;8(6):1-9. https:// doi.org/10.1371/journal.pone.0066335 ; PMid:23762487 PMCid:PMC3676365.

15. Singal GL, Nanda A, Kotwani A. A comparative evaluation of price and quality of some branded versus branded-generic medicines of the same manufacturer in India. Indian J Pharmacol. 2011;43(2):131-6. doi: 10.4103/0253-7613.77344. https://doi.org/10.4103/0253-7613.77344. 
16. Al-Gedadi NA, Hassali MA, Shafie AA. A pilot survey on perceptions and knowledge of generic medicines among consumers in Penang, Malaysia. Pharm Pract (Granada). 2008; 6: 93-97. doi: 10.4321/s1886-36552008000200006. https://doi.org/10.4321/S1886-36552008000200006.

17. Choudhry NK, Cox E, Mehta J, Shrank WH. Setting prices for generic medications: A survey of patients' perceptions. Am J Pharm Benefits. 2010;2:33-8.

18. Thomas R, Vitry A. Consumers' perception of generic medicines in community pharmacies in Malaysia. South Med Rev. 2009;2:20-3.

19. Haskins LS, Tomaszewski KJ, Crawford P. Patient and physician reactions to generics antiepileptic substitution in the treatment of epilepsy. Epilepsy Behav. 2005;7:98-105. doi: 10.1016/j.yebeh.2005.04.005. https://doi. org/10.1016/j.yebeh.2005.04.005.

20. Berg MJ, Gross RA, Haskins LS, Zingaro WM, Tomaszewski KJ. Generic substitution in the treatment of epilepsy: Patient and physician perceptions. Epilepsy Behav. 2008;13(4):693-9. doi: 10.1016/j.yebeh.2008.06.001. https://doi. org/10.1016/j.yebeh.2008.06.001.
21. Ganther JM, Kreling DH. Consumer perceptions of risk and required cost savings for generic prescription drugs. J Am Pharm Assoc (Wash). 2000;40(3):378-83. https://doi.org/10.1016/S1086-5802(16)31086-5.

22. Babar ZU, Stewart J, Reddy S et al. An evaluation of consumers' knowledge, perceptions and attitudes regarding generic medicines in Auckland. Pharm World Sci 2010;32(4):440-8. doi:10.1007/s11096-010-9402-0. https://doi. org/10.1007/s11096-010-9402-0.

23. Garcia $\mathrm{CH}$, Espinoza SE, Lichtenstein M, Hazuda HP. Health literacy associations between hispanic elderly patients and their caregivers. J Health Commun. 2012;18(Suppl 1):256-72. doi: 10.1080/10810730.2013.829135. https://doi.org/1 $0.1080 / 10810730.2013 .829135$.

24. Chong $C P$, Hassali MA, Bahari MB, Shafie AA. Exploring community pharmacists' views on generic medicines: a nationwide study from Malaysia. Int J Clin Pharm. 2011;33(1):124-31. doi: 10.1007/s11096-010-9470-1. https://doi. org/10.1007/s11096-010-9470-1.

Article History: Submission Date : 07-02-17; Revised Date : 19-03-17; Acceptance Date : 16-04-17.

Cite this article: Stuart AV, Gupta MM, Sealy P. Patients' Perception of Generic Drugs at Health Institutions in Trinidad and Tobago. JYoung Pharm. 2017;9(3):362-

6. 